\title{
Application of Cavity Expansion Theory in Predicting Centrifuge Cone Penetration Resistance
}

\author{
M.W. Gui ${ }^{1}$ and D.S. Jeng ${ }^{2, *}$ \\ ${ }^{1}$ Department of Civil Engineering, National Taipei University of Technology, Taipei 106, Taiwan \\ ${ }^{2}$ Division of Civil Engineering, University of Dundee, Dundee, Scotland, UK
}

\begin{abstract}
In this paper, a simple model for the prediction of centrifuge cone penetration tip resistance in sand is presented. The proposed method, which relates the tip resistance to the pressure to expand a spherical cavity, refines and simplifies Greeuw's original equations. The method assumed the failure mode of a spherical cavity expansion pressure given as a function of shear stiffness, angle of friction and compressibility of the soil. The proposed method provides a better prediction of tip resistance by taking into account soil compressibility and the decrease of angle of friction with increasing mean normal stress. The proposed approach is verified via the comparison of the predicted results with the results from a series of centrifuge cone penetration tests.
\end{abstract}

\section{INTRODUCTION}

Inadequacy of conventional laboratory testing and inevitable disturbance of soil samples have led to the development and growth of in-situ testing devices. One of these devices, the cone penetrometer, has undergone tremendous development in recent years and has been transformed from a somewhat primitive tool into a highly sophisticated instrument. Penetrometers can be used to study the stratification of soil because of their capability of providing a continuous measurement over the whole depth of penetration. Simplicity of the test procedure, increased reliability of the test data and increased pushing capacity of the equipment has made it a very popular device, especially in offshore site investigation work.

A rigorous theoretical analysis of cone penetration is extremely difficult because of the large strains and material non-linearity associated to the problem [1]. There are many approximate theoretical correlations proposed since the early 1960. Some of them have been widely used in practice, for example, [2-4]. As summarized by Yu and Mitchell [1], the analysis of cone penetration in undrained clay and fully drained sands can be divided into five categories, i.e. bearing capacity theory, cavity expansion theory, steady state deformation, incremental finite-element analysis, and calibration chamber testing.

Based on the observation that the pressure required to produce a deep hole in an elastic-plastic medium is proportional to the required pressure of expanding a cavity of the same volume under the same conditions, the analogy between the cavity expansion and cone penetration was presented in [5]. The use of cavity expansion theory to predict

*Address correspondence to this author at the Department of Civil Engineering, National Taipei University of Technology, Taipei 106, Taiwan; Tel: +886 955154891; Fax: +886 227814518; E-mail: mwgui@ntut.edu.tw and Division of Civil Engineering, University of Dundee, Dundee, Scotland, UK; Tel: +44 1382 386141; Fax: +44 1382 385816;

E-mail: d.jeng@dundee.ac.uk cone penetration resistance involves the determination of the cavity expansion limit pressure, and then relating the limit pressure to the cone penetration resistance. The method has been used by many researchers [6-17].

The spherical cavity expansion theory has seldom been adopted by centrifuge modelers in analyzing their test results, except Lee [9]. One of the reasons is the highly nonlinearity nature of the test that is associated with the centrifuge environment. It is difficult to determine the correct stress state and soil properties for analysis of data from centrifugal tests. The cone penetration resistance profile obtained from a calibration chamber test normally shows a constant tip resistance value with penetration depth. Thus, it is more certain to obtain the stress state and soil properties for the analysis of calibration chamber data than the centrifuge data.

In this paper, based on the cavity expansion theory, a closed form analytical solution for the analysis of cone penetration resistance in cohesionless material is presented. First, a brief of the centrifuge cone penetration is given. Then, the derivation of the close form solution is presented. The predicted results were then compared with the results obtained from four cone penetration tests conducted in the centrifuge.

\section{CENTRIFUGE CONE PENETRATION TESTS}

Centrifuges have been widely applied to model geotechnical problems because the behavior of a foundation can be observed in a soil specimen of known parameters without the expense and delay of doing full-scale tests. Four cone penetration tests had been conducted in geotechnical centrifuge using the Fontainbleau sand from France. The diameter in the particle-size distribution curve corresponding to $50 \%$ finer of the sand $\left(D_{50}\right)$ was $0.181 \mathrm{~mm}$ and the coefficient of uniformity of the sand $\left(\mathrm{d}_{60} / \mathrm{d}_{10}\right)$ was 1.69 . The average specific gravity of the sand $\left(\mathrm{G}_{\mathrm{s}}\right)$ was 2.644 . The average values of maximum $\left(\mathrm{e}_{\max }\right)$ and minimum $\left(\mathrm{e}_{\min }\right)$ void ratios were 0.55 and 0.92 respectively. 
Four sets of data obtained from centrifuge cone penetration tests have been chosen for analysis in this study. The test specimens were prepared by hand pluviating Fontainbleau sand from a single-hole hopper into a cylindrical tub of $850 \mathrm{~mm}$ in diameter. All the test specimens have an average height of $350 \mathrm{~mm}$. Only one cone penetration test was conducted at center of each specimen under a nominal acceleration of $70 \mathrm{~g}$. All the four cone penetration tests were performed using a $10 \mathrm{~mm}$ diameter cone penetrometer. Detailed description of centrifuge cone penetration tests can be found in Bolton et al. [18]. The test results for all the four cone penetration tests are presented in Fig. (1). For test T1: dry density $=1663 \mathrm{~kg} / \mathrm{m}^{3}$, void ratio $\mathrm{e}=0.59$, and relative density $\mathrm{I}_{\mathrm{D}}=89 \%$; for test $\mathrm{T} 2$ : dry density $=1631 \mathrm{~kg} / \mathrm{m}^{3}$, void ratio $\mathrm{e}=0.62$, and relative density $\mathrm{I}_{\mathrm{D}}=81 \%$; for test $\mathrm{T} 3$ : dry density $=1552 \mathrm{~kg} / \mathrm{m}^{3}$, void ratio $\mathrm{e}=0.70$, and relative density $\mathrm{I}_{\mathrm{D}}=58 \%$; and for test $\mathrm{T} 4$ : dry density $=1538 \mathrm{~kg} / \mathrm{m}^{3}$, void ratio $\mathrm{e}=0.72$, and relative density $\mathrm{I}_{\mathrm{D}}=54 \%$. The calculation of the void ratio was based on the overall weight of the specimen and its volume measured after the specimen was mounted on to the centrifuge arm. All the tests, except test in specimen with relative density $I_{D}=54 \%$, exhibit a uniform tip resistance profile, which means these specimens have a consistent relative density throughout the specimen depth. As for test $\mathrm{T} 4\left(\mathrm{I}_{\mathrm{D}}=54 \%\right)$, the non-uniform profile shows that the specimen has an inconsistent relative density throughout its depth.

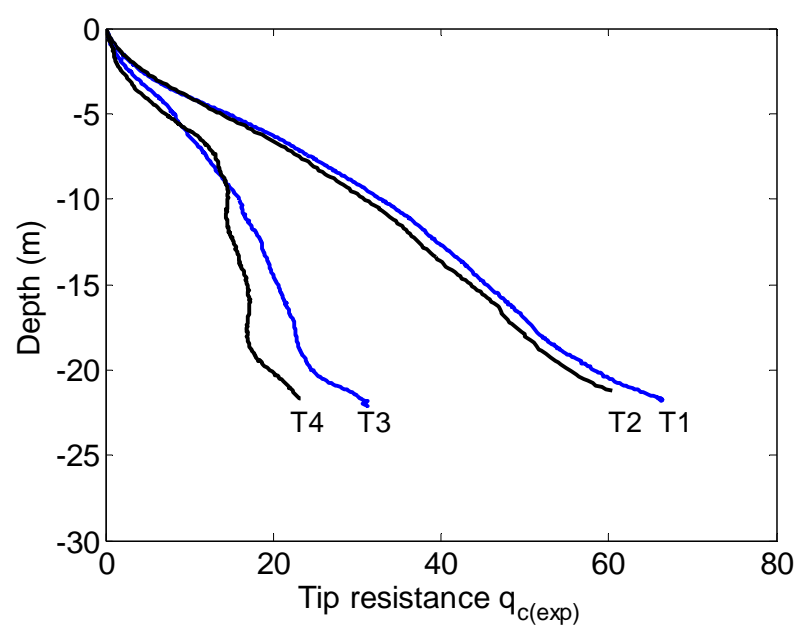

Fig. (1). Result of the centrifuge cone penetration tip resistance.

In this study, the tip resistance results back estimated from the cavity expansion theory are compared with those obtained from the centrifuge tests. Since it is impossible to measure the in situ mean effective stress in the test specimens, experimental tip resistance $q_{c(\exp )}$ and vertical stress $\sigma_{v}$ are used here to estimate the angle of friction $\phi$ [19] for used in the following analysis:

$\phi=3\left(I_{D}\left(10-\ln \sqrt{q_{c(\exp )} \sigma_{v}}\right)-1\right)+\phi_{c r i t}$

$\psi=\phi-\phi_{\text {crit }}$

where $\psi$ is the angle of dilation and $\phi_{c r i t}$ is the critical angle of shearing. $\phi_{c r i t}$ of the Fontainbleau sand used is taken to be $32^{\circ}$. Equation (1) relates the relative density, tip resistance and overburden stress to the angle of friction of a soil. As seen from Fig. (2), the calculated angle of friction $\phi$ exhibits non-linearity with the mean effective stress. Another parameter, the secant shear modulus at 50\% ultimate shear stress $G_{50}$, had been determined from a series of laboratory triaxial test as:

$G_{50}=\frac{237.5 \sqrt{\sigma_{o}}}{e^{4}(1+v)}$

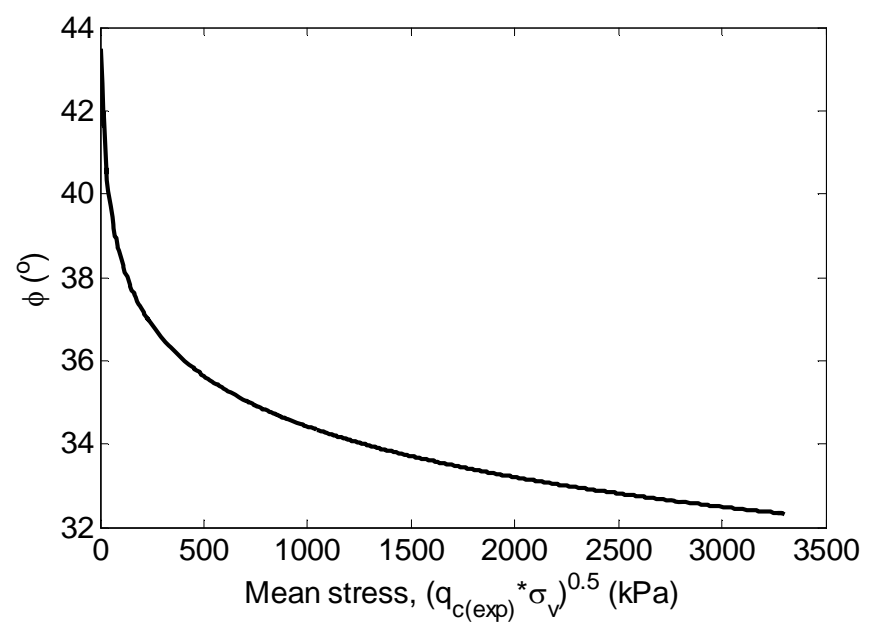

Fig. (2). Non-linear variation of angle of friction with mean effective stress for specimen with $\mathrm{I}_{\mathrm{D}}=58 \%$.

\section{THEORY OF CAVITY EXPANSION}

Carter et al. [7] assumed that the cavity is expanded in an infinite medium that is initially in a hydrostatic stress state, i.e. $\sigma_{1}=\sigma_{2}=\sigma_{3}=p_{o}$, where $\sigma_{1}, \sigma_{2}$, and $\sigma_{3}$ are the principal stress components. They pointed out that the analysis is applicable to deep cavities since any variation in stress as body forces can be neglected. In addition, the analysis allows a one-dimensional description of the problem because the displacements in the radial direction are more important than others. This assumption simplifies the analysis.

Herein, following [7], consider a spherical cavity of initial radius $a_{o}$ that can be expanded by a uniformly distributed internal pressure $p_{o}$. At a particular time $t$, the cavity enlarged to radius $a$ (Fig. 3), while the internal pressure increased to $p$. In the absence of body forces, the total stress at this point must be in equilibrium and satisfies

$\frac{d \sigma_{r}}{d r}+\frac{2\left(\sigma_{r}-\sigma_{\theta}\right)}{r}=0$

where $\sigma_{r}$ and $\sigma_{\theta}$ are the major and minor principal stresses during cavity expansion, and $r$ is the radial distance to the center of the cavity. The boundary conditions are $\sigma_{r}=p$ at $r=a$ and $\sigma_{r}=p_{o}$ at $r=\infty$. For $r>R$ the soil mass remains in a state of elastic equilibrium.

In this study, soil was modeled as an isotropic, elasticperfectly plastic material where the soil initially behaves elastically and obeys Hooke's law until the onset of yielding which is defined by 


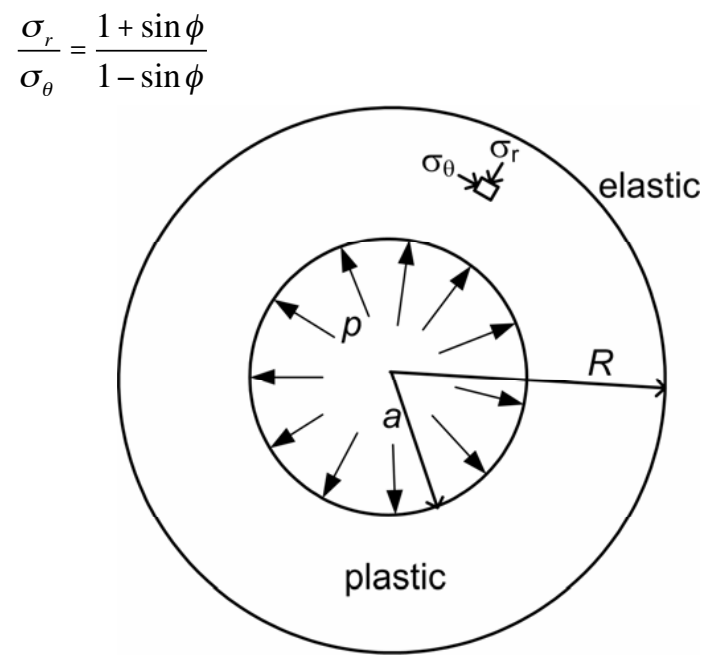

Fig. (3). Cavity expansion problem (after [7]).

\section{Determination of Limit Pressure}

To estimate the tip resistance, the limiting pressure caused by the expansion of a spherical cavity must be calculated. For an infinite deformation Carter et al. [7] found that the cavity pressure approaches a limiting value. They assumed that a steady state deformation mode is approached at very large deformations. They employed the non associated Mohr-Coulomb yielding criterion into their formulation in order to take into account the dilatancy behaviour of the sand in the analysis. Detailed derivation of their formulation can be found in Carter et al. [7]. For convenience of referencing, their relationship between the limiting pressure $P_{L}$ and the mean stress $\sigma_{o}$ is repeated here:

$$
\frac{2 G}{\sigma_{o}}=\frac{N-1}{N+2}\left[T\left(\frac{P_{L}}{\sigma_{R}}\right)^{\gamma}-Z\left(\frac{P_{L}}{\sigma_{R}}\right)\right]
$$

where $G$ is the shear modulus of the soil and

$$
\begin{aligned}
& M=\frac{1+\sin \psi}{1-\sin \psi}, N=\frac{1+\sin \phi}{1-\sin \phi}, Z=\frac{6 X}{\alpha+\beta} \\
& X=\frac{2(1-v)-2 v(M+N)+M N}{(1+v) M N} \\
& T=3\left(1+\frac{2 X}{\alpha+\beta}\right), \gamma=\frac{1+\alpha}{1-\beta} \\
& \sigma_{R}=\frac{3 N}{N+2} \sigma_{o}, \alpha=\frac{2}{M}, \beta=\frac{2-N}{N}
\end{aligned}
$$

The above expressions can be used to determine the value of $P_{L} / \sigma_{o}$ for specific values of $G / \sigma_{o}, v, \phi$ and $\psi$. Using an iterative procedure, Greeuw et al. [8] adopted Eqs. (6)-(10) to obtain the limit pressure for the analysis of their calibration chamber cone penetration data. This study overcomes the iterative procedure by further simplifying and rearranging Eq. (6) into the following analytical solution

$$
\frac{P_{L}}{\sigma_{o}}=\left[\left(\frac{N+2}{3 N}\right)^{1-\gamma}\left(1-\frac{3}{T}\right) \frac{G}{\sigma_{o}} \frac{3-\sin \phi}{T \sin \phi}\right]^{(\gamma-1)}
$$

\section{Determination of Cone Tip Resistance}

Vesic [6] applied the spherical expansion model to analyze the tip resistance of a flat-ended pile. From the observations on models and full-size piles, he concluded that the advancement of the pile in dense soil is made possible by lateral expansion of soil as well as by any possible dilation/compression. The stress induced at the base of the pile can be assumed to be equal to the limiting pressure needed to expand a spherical cavity in an infinite soil mass. The formula for the resistance at the tip of a pile $q_{o}$ has been given by Vesic [6] as:

$q_{o}=N_{\text {pile }} \sigma_{o}$

where

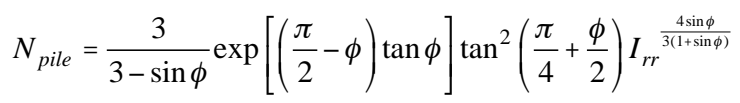

where $I_{r r}$ is a rigidity index, and $\sigma_{o}$ is the mean normal ground stress, which is correlated to the effective vertical stress $\sigma_{v}$ via

$\sigma_{o}=\left[\frac{1+2(1-\sin \phi)}{3}\right] \sigma_{v}$

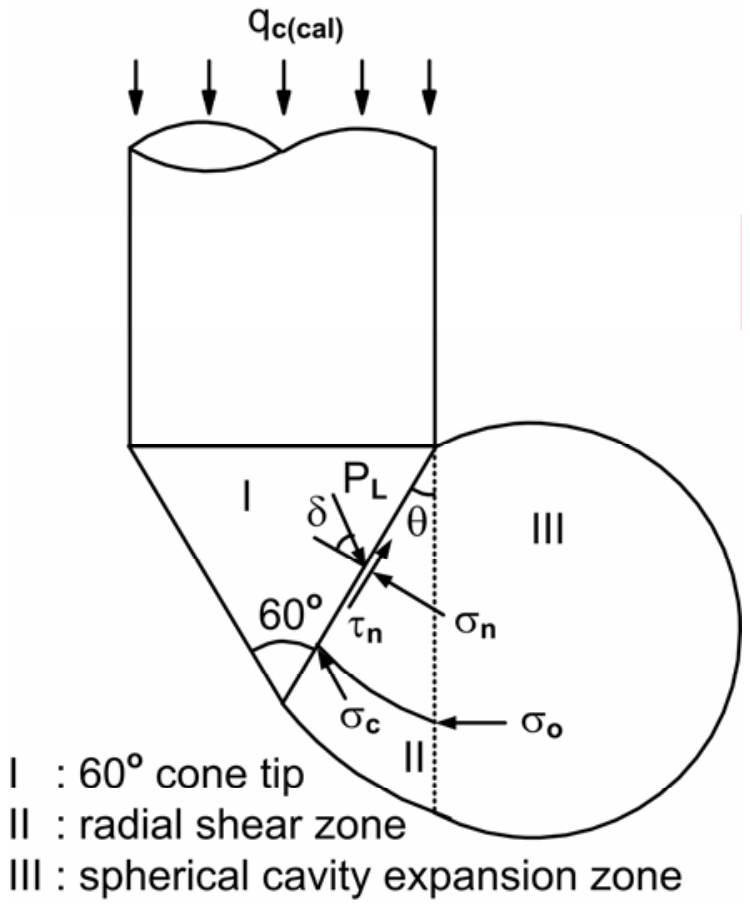

Fig. (4). Failure pattern of a cone in sand, where $\sigma_{n}$ and $\tau_{n}$ are the normal and shear stresses acting on the surface of the $60^{\circ}$ cone, $\theta$ is the angle of the radial shear zone, $\sigma_{c}$ is the mean stress acting on the $60^{\circ}$ cone in the plastic zone, and $\delta$ is the surface roughness of the cone (after [9]).

Greeuw et al. [8] used Eqs. (12) and (13) without the rigidity index term $I_{r r}$, to predict their calibration chamber cone penetration resistance. However, the calculation was, perhaps, incorrect because $N_{\text {pile }}$ was derived based on the geometry of a flat-ended pile. In order to incorporate the geometry and surface roughness of the cone (Fig. (4)), 
Vesic's [6] formula for the pile-tip resistance - Eqs. (12) and (13) - must firstly be modified. The modification involved the assumption that the soil adjacent to the cone is highly sheared and full strength is mobilized [9]. For a smooth cone, the mean stress $\sigma_{c}$ acting on a $60^{\circ}$ cone in the plastic zone is

$\sigma_{c}=\sigma_{o} \exp (2 \theta \tan \phi)$

where $\sigma_{o}$ is the mean stress at the transition surface and $\theta=60^{\circ}$. Combining the Haar and von Karman's hypothesis:

$\sigma_{o}=\frac{2 \sigma_{\theta}+\sigma_{r}}{3}$

and the Mohr-Coulomb failure criterion, Lee [9] obtained $\sigma_{o}$ as

$\sigma_{o}=\frac{3-\sin \phi}{3(1+\sin \phi)} \sigma_{r}$

As a result of putting $\sigma_{r}$ approaches the limit pressure $P_{L}$ at the plastic state Lee [9] obtained the theoretical tip resistance $q_{c(c a l)}$ as

a

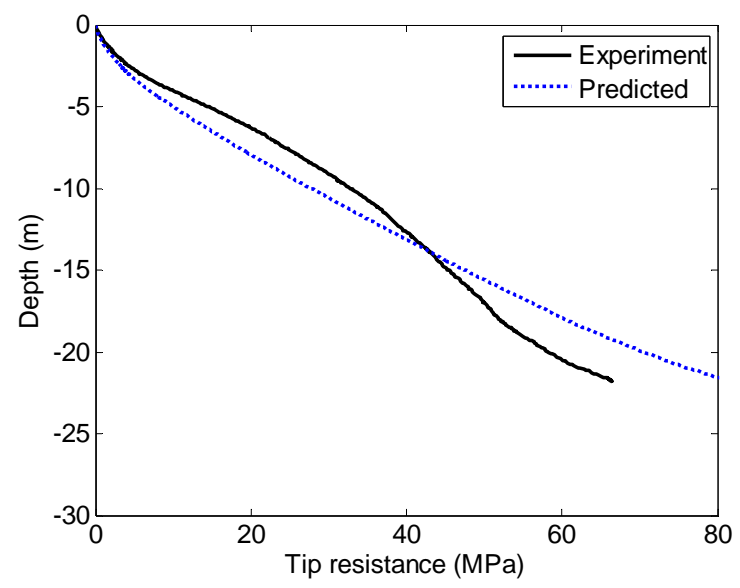

c

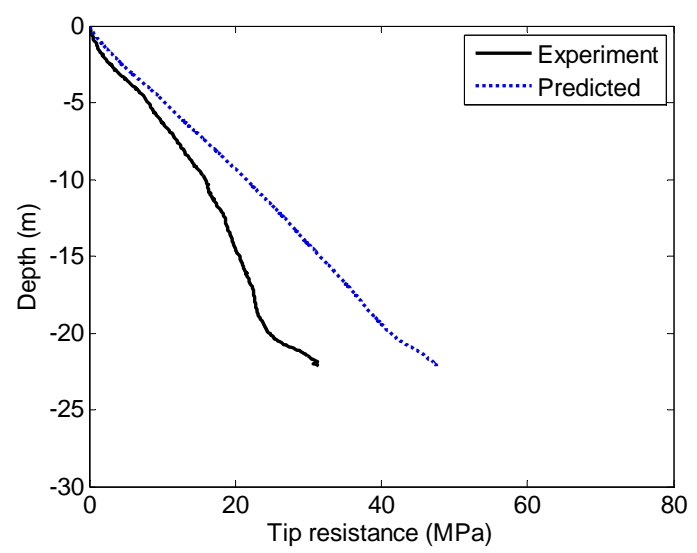

$q_{c(c a l)}=N_{c p t} P_{L}$

where

$N_{c p t}=\frac{\cos \left(\delta-60^{\circ}\right)}{\cos 60^{\circ}} \frac{\sin (\Delta+\delta)}{\sin \Delta} \frac{3-\sin \phi}{3(1+\sin \phi)} e^{2 \theta \tan \phi}$

and $\Delta=\sin ^{-1}\left(\frac{\sin \delta}{\sin \phi}\right)$. The surface roughness of the cone $\delta$ was taken to be a function of the angle of friction, which was $\phi / 3$, in this study; hence, the cosine term in the right hand side of the equation takes into consideration the geometry and the surface roughness of the cone.

\section{RESULTS AND DISCUSSION}

Arm with Eqs. (7)-(11) and Eqs. (18)-(19), it is possible to predict each of the profile of the centrifuge cone penetration tip resistance. The four predicted profiles together with the corresponding centrifuge cone penetration profiles are shown separately in Fig. (5a)-(5d) for ease of comparisons. The predicted profiles for specimens with relative density $I_{D}$ of $89 \%$ (Fig. 5a) and $81 \%$ (Fig. 5b) seem to underestimate

b

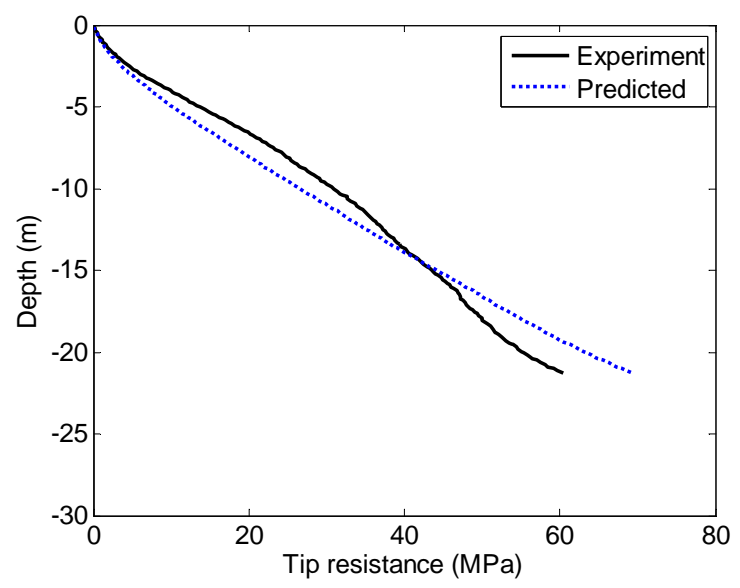

d

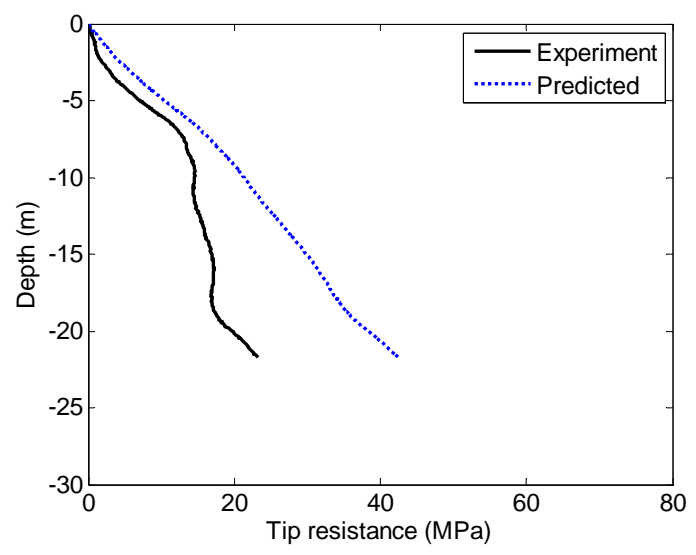

Fig. (5). (a). Comparison of predicted and measured cone resistance profiles for specimen with $\mathrm{I}_{\mathrm{D}}=89 \%$. (b). Comparison of predicted and measured cone resistance profiles for specimen with $\mathrm{I}_{\mathrm{D}}=81 \%$. (c). Comparison of predicted and measured cone resistance profiles for specimen with $\mathrm{I}_{\mathrm{D}}=58 \%$. (d). Comparison of predicted and measured cone resistance profiles for specimen with $\mathrm{I}_{\mathrm{D}}=54 \%$. 
the centrifuge results for the first $14 \mathrm{~m}$ of penetration. Thereafter, the predicted profiles begin to overestimate the centrifuge results. For specimens with relative density $I_{D}$ of $89 \%$ and $81 \%$, the predicted result was, respectively, roughly within $\pm 25 \%$ and $\pm 15 \%$ of the centrifuge result.

For specimens with relative density $\mathrm{I}_{\mathrm{D}}$ of $58 \%$ (Fig. 5c) and $54 \%$ (Fig. 5d), the predicted results overestimated the centrifuge results as soon as the penetration started. For specimens with relative density $\mathrm{I}_{\mathrm{D}}$ of $58 \%$ and $54 \%$ the predicted result overestimated the centrifuge result by a maximum of $68 \%$ and $100 \%$, respectively. The reason for the underestimation of the centrifuge results for the first $14 \mathrm{~m}$ of penetration in the very dense specimens is not so clear but one of the reasons for the overestimation in the medium dense specimens could be the overlooking of the effect of compressibility of the medium dense soil in Eq. (18). The significance of compressibility on the bearing capacity of shallow foundations on Fontainbleau sand had been pointed put by [20] and this effect will be incorporated and examined in the following section.

\section{Effect of Compressibility}

To account for the effect of compressibility in cone penetration resistance, the modified bearing capacity formula proposed by Vesic [21] is adopted here

$\mathbf{a}$

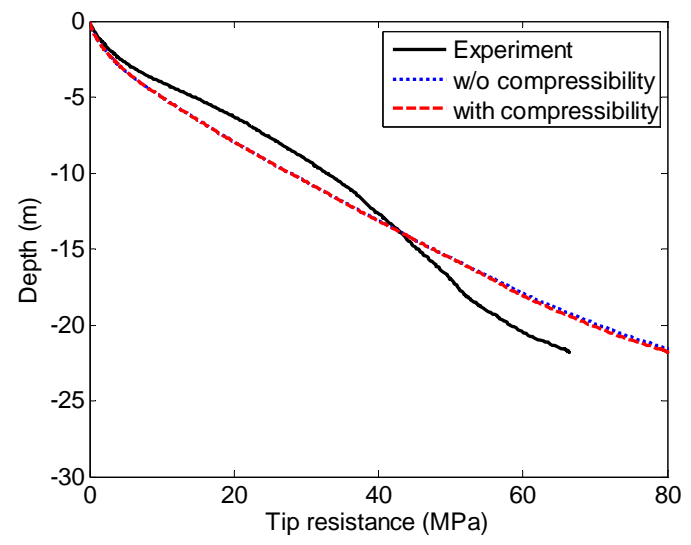

c

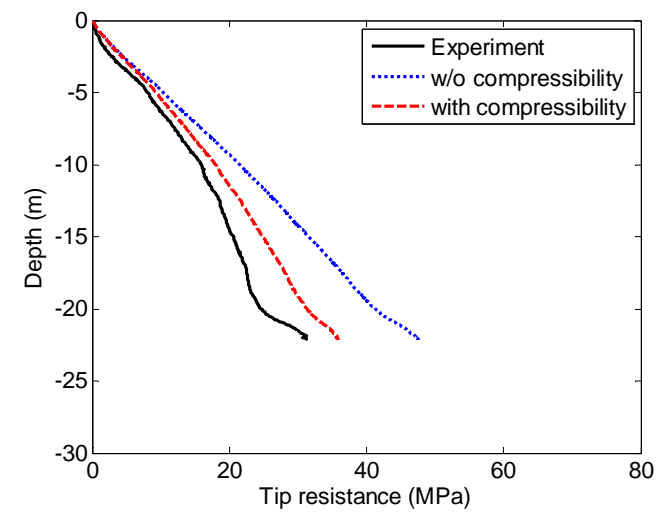

$q_{c(\text { comp })}=q_{c(\text { cal })} F_{\text {comp }}$

where $q_{c(\text { comp })}$ is the tip resistance after considering the effect of soil compressibility and $F_{\text {comp }}$ is the soil compressibility factor, which is given by [21]

$$
F_{\text {comp }}=\exp \left\{\left(\frac{(3.07 \sin \phi)\left(\log 2 I_{r}\right)}{1+\sin \phi}\right)-3.8 \tan \phi\right\} \leq 1.0
$$

where $I_{r}$ is the rigidity index, which is given by

$$
I_{r}=\frac{G_{50}}{\sigma_{v} \tan \phi}
$$

The rigidity index varies with the stress level and the characteristic of loading. A higher value of $I_{r}$ implies a relatively incompressible material while a lower value implies a relatively compressible material.

Figs. (6a)-(6d) show the effect of the compressibility on the calculated tip resistance profiles. Fig. (6a) shows that for a very dense specimen $\left(I_{D}=89 \%\right)$, there is virtually no compressibility effect $\left(F_{\text {comp }}=1\right)$ because the soil is too dense to allow for any compression to occur. Fig. (6b) shows that for a slightly looser (in relative to $\mathrm{I}_{\mathrm{D}}=89 \%$ ) specimen with $\mathrm{I}_{\mathrm{D}}=$ $81 \%$, the effect of compressibility begin to appear, albeit

b

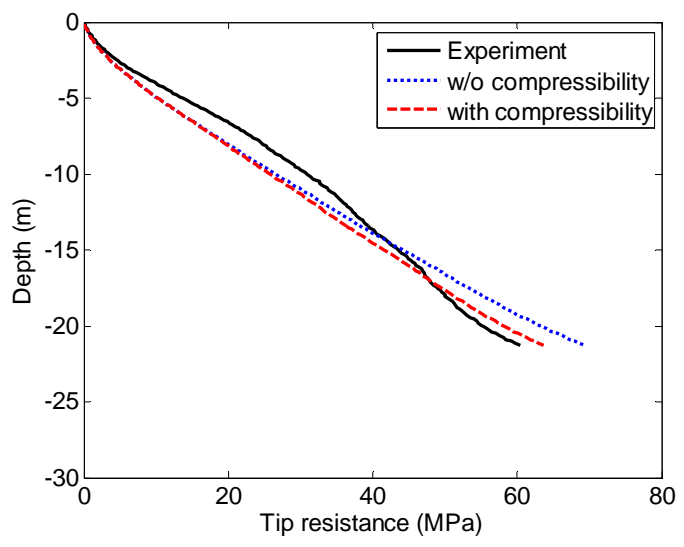

d

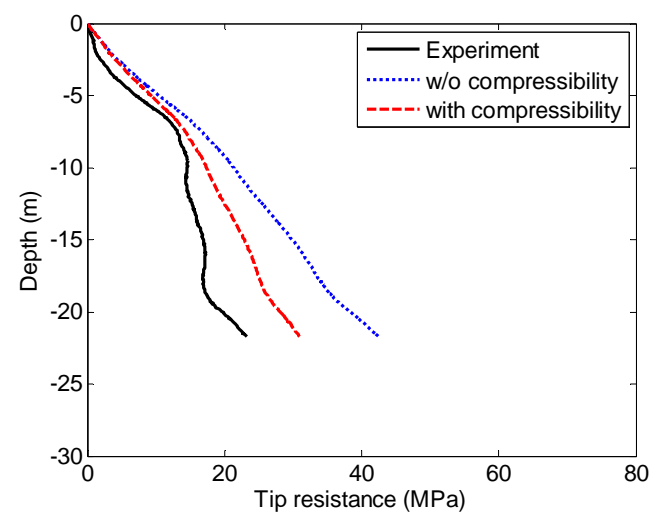

Fig. (6). (a). Effects of compressibility on the predicted cone resistance profile for specimen with $\mathrm{I}_{\mathrm{D}}=89 \%$. (b). Effects of compressibility on the predicted cone resistance profile for specimen with $\mathrm{I}_{\mathrm{D}}=81 \%$. (c). Effects of compressibility on the predicted cone resistance profile for specimen with $\mathrm{I}_{\mathrm{D}}=58 \%$. (d). Effects of compressibility on the predicted cone resistance profile for specimen with $\mathrm{I}_{\mathrm{D}}=54 \%$. 
very little $\left(0.92<F_{\text {comp }}<0.96\right)$ for penetration depth between 17 to $22 \mathrm{~m})$.

The contribution of the compressibility effect is more significant in the medium dense specimen than the very dense specimen. This effect can be clearly seen in Figs. (6c) and (d) for both the medium dense specimens $\left(\mathrm{I}_{\mathrm{D}}=58 \%\right.$ and $54 \%)$. $F_{\text {comp }}$ was found to be between 1.0 and 0.76 for penetration depth between 0 to $22 \mathrm{~m}$ for specimen with $I_{D}=$ $58 \%$., and it was found to be between 1.0 and 0.73 for penetration depth between 0 to $22 \mathrm{~m}$ for specimen with $\mathrm{I}_{\mathrm{D}}=54 \%$. After considering the effect of compressibility the overestimation of the cone resistance is now $27 \%$ and $55 \%$ for test in specimen with $\mathrm{I}_{\mathrm{D}}=58 \%$ and $54 \%$, respectively.

\section{CONCLUSIONS}

An analytical solution, based on the spherical cavity expansion model used by Carter et al. [7], has been proposed and used to predict the profile of centrifuge cone penetration resistance. The model previously proposed by Greeuw et al. [8] not only required an iterative procedure to obtain the limit pressure but also adopted a pile factor, instead of a cone factor, to correlate this limit pressure to the cone resistance. This study improved this shortcoming by adopting a cone factor that was derived based on the geometry of the cone. In its original form, the current analytical formulation overestimated the tip resistance of medium specimens by about $68 \%$ and $100 \%$. After incorporating the effect of compressibility into the formulation, the overestimation of the cone resistance reduced to $27 \%$ and $55 \%$ for test specimen with relatively density $\mathrm{I}_{\mathrm{D}}$ of $58 \%$ and $54 \%$, respectively. The prediction of cone resistance for very dense specimen remains basically the same with or without considering the compressibility effect since the very dense specimen is relatively incompressible.

\section{ACKNOWLEDGEMENTS}

The study presented herein is based on a collaborative research that was initiated at The University of Sydney. The first author is grateful to The University of Sydney, for providing the computer and software access and other assistances while he was a Visiting Scholar there, and NTUT, for granting him the study leave.

\section{REFERENCES}

[1] H. S. Yu, and J. K. Mitchell, "Analysis and cone resistance: review of methods", J. Geotech. Geoenviron. Eng. ASCE, vol. 124(2), pp. 140-149, Feb 1998.

[2] H.T. Durgunoglu, and J.K. Mitchell, "Static penetration resistance of soils. I: Analysis", in ASCE special conference on in situ meas- urement of soil properties, ASCE, vol. 1, New York, pp. 151-171, 1975.

[3] J. K. Mitchell, and J. M. Keaveny, "Determining sand strength by penetrometers", in ASCE special conference on use of in situ tests in geotechnical engineering, geotechnical special publication no. 6, ASCE, New York, pp. 823-839, 1986.

[4] M. Jamiolkowski, V. N. Ghionna, R. Lancellotta, and E. Pasqualini, "New correlations of penetration tests for design practice", in First international symposium on penetration testing, ISOPT-1, orlando, A. A. Balkema, Rotterdam, Netherlands, vol. 1, pp. 263-301, March 1988.

[5] R. F. Bishop, R. Hill, and N. F. Mott, "Theory of Indentation and hardness tests", Proc. Phys. Soc., vol. 57, pp. 147-159, 1945.

[6] A.S. Vesic, "Expansion of cavities in infinite soil mass", J. Soil Mech. Found. Div. ASCE, vol. 98(SM3), pp. 265-290, 1972.

[7] J. P. Carter, J. R. Booker, and S. K. Yeung, "Cavity expansion in cohesive frictional soils", Géotechnique, vol. 36(3), pp. 349-358, 1986.

[8] G. Greeuw, F. P. Smits, and P. van Driel, "Cone penetration tests in dry Osterschelede sand and the relation with a cavity expansion model", in First international symposium on penetration testing, ISOPT-1, Orlando, A. A. Balkema, Rotterdam, Netherlands, vol. 2, pp. 771-776, March 1988.

[9] S. Y. Lee, "Centrifuge modeling of cone penetration testing in cohesionless soils", Ph.D. thesis, Cambridge University, U.K., 1990.

[10] H. S. Yu, and G. T. Houlsby, "Finite cavity expansion in dilatant soils: Loading Analysis", Geotéchnique, vol. 41(2), pp. 173-183, 1991.

[11] I. F. Collins, M. J. Pender, and Y. Wang, "Cavity expansion in sands under drained loading conditions", Int. J. Num. Anal. Meth. Geomech., vol. 16(1), pp. 3-23, 1992.

[12] I. F. Collins, and H. S. Yu, "Undrained cavity expansions in critical state soils", Int. J. Num. Anal. Meth. Geomech., vol. 20(7), pp. 489516, 1996.

[13] R. Salgado, J. K. Mitchell, and M. Jamiolkowski, "Cavity expansion and penetration resistance in sand", J. Geotech. Geoenviron. Eng. ASCE, vol. 123(4), pp. 344-354, 1997.

[14] R. Salgado, J. K. Mitchell, and M. Jamiolkowski, "Calibration chamber size effects on penetration resistance in Sand", J. Geotech. Geoenviron. Eng. ASCE, vol. 124(9), pp. 878-888, Sept 1998.

[15] H. H. Hsu, and A. B. Huang, "Calibration of cone penetration tests in sand", Proc. Natl. Sci. Coun. ROC (A), vol. 23(5), pp. 579-590, 1999.

[16] R. Salgado, and M. F. Randolph, "Analysis of cavity expansion in sand,” Int. J. Geomech., vol. 1(2), pp. 175-192, 2001.

[17] A. B. Huang, and H. H Hsu, "Cone penetration tests under simulated field conditions," Géotechnique, vol. 55(5), pp. 345-354, 2005.

[18] M. D. Bolton, M. W. Gui, J. Garnier, J. F. Corte, G. Bagge, J. Laue, and R. Renzi, "Centrifuge cone penetration tests in sand," Géotechnique, vol. 49(4), pp. 543-552, 1999.

[19] M. D. Bolton, M. W. Gui, and R. Phillips, "Review of miniature soil probes", in Eleventh south east asia geotechincal conference, Singapore, pp. 85-91, May 1993.

[20] M. W. Gui, and B. Muhunthan, "Bearing capacity of foundations on sand using the method of slip line", J. Marine Sci. Technol., vol. 14(1), pp. 1-14, 2006.

[21] A.S. Vesic, "Analysis of ultimate loads of shallow foundations", $J$. Soil Mech. Found. Div. ASCE, vol. 99(SM1), pp. 45-73, 1973. 